\title{
Influência do óleo essencial na micorrização e no crescimento de mudas de eucalipto
}

\author{
Ricardo Bemfica Steffen ${ }^{1}$, Zaida Inês Antoniolli ${ }^{1}$, Gerusa Pauli Kist Steffen ${ }^{1}$, Rodrigo Josemar Seminoti Jacques ${ }^{1}$, \\ Daniel Pazzini Eckardt ${ }^{1}$, Marcos Leandro dos Santos ${ }^{1}$, Natielo Almeida Santana ${ }^{1}$ \\ 1Universidade Federal de Santa Maria (UFSM), Departamento de Solos, Centro de Ciências Rurais, Bairro Camobi, 1000, CEP 97105-900, Santa Maria, \\ Rio Grande do Sul, Brasil
}

"Autor correspondente:

bemfica_steffen@yahoo.com.br

Termos para indexação:

Ectomicorrizas

Simbiose

Metabólitos secundários

Index terms:

Ectomycorrhizae

Symbiosis

Secondary metabolites

Histórico do artigo:

Recebido em 29 mar 2011

Aprovado em 26 ago 2011

Publicado em 30 set 2011

doi: 10.4336/2011.pfb.31.67.235
Resumo - O estabelecimento das essências florestais exóticas pode apresentar dependência da associação ectomicorrízica, a qual eleva a resistência das mudas aos estresses iniciais após o plantio no campo, favorecendo o desenvolvimento inicial das mudas sob condições adversas. O trabalho objetivou avaliar o efeito da aplicação do óleo essencial de eucalipto na colonização ectomicorrízica e no crescimento de mudas de Eucalyptus grandis, em condições de casa de vegetação. Os tratamentos foram constituídos por cinco concentrações do óleo essencial de Eucayptus grandis e dois isolados ectomicorrízicos, além dos tratamentos controle sem inoculação. Utilizou-se delineamento experimental inteiramente casualizado com oito repetições. Noventa dias após o transplante das plântulas de eucalipto para tubetes foram avaliados os parâmetros: altura da muda $(\mathrm{cm})$, diâmetro do colo $(\mathrm{mm})$, massa seca da parte aérea e raízes $(\mathrm{mg})$ e percentual de colonização ectomicorrízica. O óleo essencial de eucalipto mostrou-se eficiente no estímulo à colonização ectomicorrízica das mudas de eucalipto, resultando em aumentos significativos na colonização e na massa fresca e massa seca da parte aérea das mudas micorrizadas, apresentando resposta de dose-efeito, dependendo do isolado ectomicorrízico utilizado.

\section{Essential oil influence in mycorrhizal colonization and growth seedlings of eucalyptus}

\begin{abstract}
The establishment of exotic forest species in Brazil may show dependence to ectomycorrhizal association, which increases the resistance of seedlings to stress after the initial planting in the field, favoring the maintenance of harshseedlings under adverse conditions. The study aimed to evaluate the effect of applying the eucalyptus essential oil in ectomycorrhizal colonization on growth of Eucalyptus grandis seedlings in greenhouse conditions. The treatments consisted of five concentrations of the Eucayptus grandis essential oil and two ectomycorrhizal isolates, in addition to the control treatment without inoculation. It was used a completely randomized design with eight repetitions. Ninety days after transplanting the eucalyptus seedlings were evaluated: height $(\mathrm{cm})$, stem diameter $(\mathrm{mm})$, dry massof shoots and roots $(\mathrm{mg})$ and percentage of ectomycorrhizal colonization. The eucalyptus essential oil was efficient in stimulating ectomycorrhizal colonization of eucalyptus seedlings, resulting in significant increases in dry weight of shoots of mycorrhizal seedlings, showing doseresponse effect, depending on the ectomycorrhizal used.
\end{abstract}




\section{Introdução}

Um povoamento florestal bem formado é diretamente proporcional à qualidade das mudas das essências florestais utilizadas, sendo que estas devem apresentar vigor suficiente para resistir ao estresse inicial após o transplante (Trevisan et al., 2007). Em decorrência disso, buscam-se alternativas tecnológicas para produção de mudas de qualidade (Pêra \& Parladé, 2005). Segundo Bâ et al. (2010) o estabelecimento de muitas essências florestais exóticas somente é possível devido à associação das plantas com fungos ectomicorrízicos (fECM) capazes de proporcionar as condições necessárias para a manutenção das plantas no campo. Em virtude disso, a micorrização controlada apresenta-se como uma ferramenta fundamental, tornando possível o estabelecimento de mudas florestais em solos com condições de deficiência de nutrientes ou mesmo na presença de alguns poluentes (Pêra \& Parladé, 2005; Tarkka et al., 2005; Hobbie, 2006; Brundrett, 2009; Mello et al., 2009; Alves et al., 2010).

Dentre os fungos do solo capazes de formar associações ectomicorrízicas, os do gênero Pisolithus apresentam ampla distribuição geográfica, sendo capazes de formar associação simbiótica com aproximadamente 450 espécies florestais, especialmente as de interesse econômico pertencentes às famílias Pinaceae e Myrtaceae (Pereira et al., 2005; Smith \& Read, 2008). Devido a isto, o gênero Pisolithus é um dos mais utilizados em estudos quanto à colonização micorrízica e em programas de micorrização controlada (Pereira et al., 2005; Yuwa-Amornpitak, 2009).

Embora os fungos do gênero Pisolithus possuam a habilidade de formar basidiósporos in situ e disseminem seus esporos no solo das comunidades florestais consolidadas, nos viveiros florestais, estes devem ser inoculados na produção de mudas, garantindo a simbiose entre fungo e planta, resultando em mudas florestais com maior vigor e aptas para o transplante em campo (Pêra \& Parladé, 2005).

No Brasil, apesar do crescente interesse pelo cultivo de essências florestais, os programas de micorrização controlada ainda são limitados, (Pereira et al., 2005). Os trabalhos encontrados na literatura sobre a otimização da colonização ectomicorrízica e, consequentemente, sobre o maior desenvolvimento das plantas inoculadas, baseiam-se nos modos de inoculação e dosagens utilizadas (Pêra \& Parladé, 2005; Rossi et al., 2007), colonização consorciada (Bonnassis, 2007), especificidade micorrízica (Meijer, 2001; Duñabeitia et al., 2004; Giachini et al., 2004; Mello et al., 2006; Souza et al., 2008) e inoculação das plantas com mais de um isolado (Probanza et al., 2001; Dormenech et al., 2004; Rincón et al., 2005).

A associação de fungos mutualistas com o sistema radicular de plantas hospedeiras representa uma estratégia adaptativa do vegetal. A produção e o acúmulo de determinados metabólitos secundários dos vegetais desempenham papel fundamental durante o processo de micorrização (Zhi-lin et al., 2007). Wenke et al. (2010), ao descreverem as funções dos compostos voláteis no solo, demonstram a importância destes nas interações formadas entre microrganismos e entre microrganismos e plantas. Segundo Ryabushkina (2005) e Wenke et al. (2010) os compostos voláteis exsudados pelas raízes devem ser considerados como sinais bioquímicos essenciais para a manutenção de ecossistemas.

A presença destes sinais bioquímicos ou "moléculas verdes" estimula a fase pré-simbiótica, desencadeando as mudanças fisiológicas e morfológicas tanto no fungo como na planta (Bécard et al., 2004; Akiyama et al., 2005; Zhi-lin et al., 2007). No entanto, os relatos sobre a utilização de compostos voláteis vegetais no estímulo à colonização micorrízica são raros (Ludley et al., 2008, 2009), sendo necessários estudos mais aprofundados, a fim de se determinar o efeito da aplicação destes extratos em mudas florestais. Neste sentido, o objetivo deste trabalho foi avaliar o efeito da aplicação do óleo essencial de eucalipto na colonização ectomicorrízica por diferentes fungos in situ e no crescimento de mudas de Eucalyptus grandis em condições de casa de vegetação.

\section{Material e métodos}

Os tratamentos foram constituídos por cinco concentrações do óleo essencial de eucalipto e dois isolados ectomicorrízicos, além do tratamento controle. Para o desenho experimental, utilizou-se o delineamento inteiramente casualizado, com oito repetições.

\section{Obtenção do óleo essencial de Eucalyptus grandis}

A extração do óleo essencial foi realizada através da técnica de hidrodestilação das folhas frescas de eucalipto. Inicialmente, coletaram-se folhas frescas de eucalipto segundo a metodologia proposta por Vitti 
\& Brito (2003), as quais foram cortadas em pedaços de $2 \mathrm{~cm}$, pesadas e separadas em lotes individuais de $100 \mathrm{~g}$. Posteriormente, as folhas foram colocadas em balão volumétrico no aparelho de Clevenger modificado (Serafini \& Cassel, 2001), mantendo-se água destilada em ebulição dentro do balão volumétrico com aquecedor externo. Os componentes vegetais líquidos extraídos, após a passagem por um condensador, foram coletados e mantidos sob refrigeração a $4{ }^{\circ} \mathrm{C}$ durante quatro dias.

As sementes de Eucalyptus grandis foram obtidas na Estação Experimental de Silvicultura de Santa Maria FEPAGRO. Para a desinfestação das sementes, as mesmas foram imersas em etanol $(70 \%)$ e hipoclorito de sódio (1\%), conforme metodologia descrita por Bonnassis (2007). Após a assepsia das sementes, estas foram prégerminadas em placas de Petri contendo solução de germinação de ácido bórico $(3 \mu \mathrm{M})$, glicose $\left(2 \mathrm{~g} \mathrm{~L}^{-1}\right)$, sulfato de cálcio $(500 \mu \mathrm{M})$ e ágar $\left(4 \mathrm{~g} \mathrm{~L}^{-1}\right)$, a $\mathrm{pH}$ 5,7.

Utilizou-se como inóculos os fECM das espécies Pisolithus sp. (UFSC Pt 24) e Pisolithus microcarpus (UFSC Pt 116). Para formação do inóculo básico, os isolados foram mantidos em meio de cultura sólido Melin-Norkrans modificado-MNM, pH 5,8 (Marx, 1969), em placas de Petri de $90 \mathrm{~mm}$ de diâmetro. O material foi colocado em estufa a $26^{\circ} \mathrm{C}$ e, posteriormente, multiplicado através de repicagens para o meio da mesma composição, sob condições assépticas.

Para produção do inoculante vegetativo de fECM, utilizou-se uma adaptação da técnica descrita por Chávez et al. (2009), sendo realizadas suspensões micelianas dos isolados UFSC Pt 116 e UFSC Pt 24 em 50 mL de meio Melin-Norkrans modificado-MNM líquido (Marx, 1969) em Erlenmeyers de $150 \mathrm{~mL}$, a partir de discos de $10 \mathrm{~mm}$ de diâmetro obtidos das culturas em placa, seguindo-se de incubação a $26{ }^{\circ} \mathrm{C}$, durante 30 dias. Após este período, o conteúdo dos Erlenmeyers foi separado por isolado e fragmentado em $200 \mathrm{~mL}$ de meio MNM líquido, em liquidificador, durante 10 segundos, e misturado a $300 \mathrm{~mL}$ de turfa estéril, em bequer de 1000 $\mathrm{mL}$. Após a fragmentação do micélio fúngico e sua homogeneização no substrato, este foi acondicionado em incubadora a $26^{\circ} \mathrm{C}$, até o momento da utilização.

Em casa de vegetação, tubetes cônicos de PVC de $100 \mathrm{~cm}^{3}$ foram dispostos sobre telado utilizado em viveiros comerciais e preenchidos $90 \%$ do seu volume com turfa. A turfa utilizada como substrato apresentou pH em água 5,8; cálcio 25,9 $\mathrm{cmol}_{\mathrm{c}} \mathrm{dm}^{-3}$; magnésio $4,7 \mathrm{cmol}_{\mathrm{c}} \mathrm{dm}^{-3} ; \mathrm{H}+\mathrm{Al} 2,5 \mathrm{cmol}_{\mathrm{c}} \mathrm{dm}^{-3}$; CTC efetiva 31,1 ; matéria orgânica $12 \%$; argila $9 \%$; potássio $176 \mathrm{mg} \mathrm{dm}^{-3} \mathrm{e}$ fósforo $11,3 \mathrm{mg} \mathrm{dm}^{-3}$.

Preenchidos os tubetes, estes foram irrigados a fim de adensar a turfa no seu interior, chegando esta a um volume aproximado de $80 \%$ do tubete. Após este processo, completou-se o volume restante dos tubetes com a turfa inoculada com os isolados ectomicorrízicos, mantendo-se o substrato úmido até o momento do transplante das plântulas de eucalipto.

\section{Germinação e crescimento de mudas de Eucalyptus grandis micorrizadas}

Decorrido o período de germinação das sementes (sete dias), as plântulas de eucalipto foram transplantadas para tubetes de plástico de $100 \mathrm{~cm}^{3}$, contendo turfa inoculada com fECM. Após o transplante, os tubetes permaneceram sobre telado em casa de vegetação. A reposição da umidade foi realizada adicionando-se diariamente $8 \mathrm{~mL}$ de água destilada aos tubetes, sendo aplicado $10 \mathrm{~mL}$ de solução nutritiva de Hoagland \& Arnon (1951) em intervalos de 25 dias por tubete.

Para avaliação do efeito da concentração do óleo essencial de eucalipto sobre o desenvolvimento das plântulas, solubilizou-se o óleo essencial em etanol $96,5 \%$ na proporção de $1: 1\left(\mathrm{v} \mathrm{v}^{-1}\right)$, conforme metodologia proposta por Fabrowski et al. (2003). Aplicou-se sobre o substrato de cada tubete, $3 \mathrm{~mL}$ do óleo solubilizado nas concentrações de $0,20,30,40$ e $50 \mu \mathrm{L} \mathrm{L}^{-1}$, sendo a concentração zero o tratamento controle em intervalos de 7 dias a contar da data de transplante das plântulas.

As avaliações foram realizadas aos 90 dias após o transplante das plântulas, sendo avaliados os parâmetros: altura da muda $(\mathrm{cm})$, diâmetro do colo (mm), massa seca da parte aérea e raízes (mg) e percentual de colonização ectomicorrízica.

Para a determinação da massa seca da parte aérea e raízes, as plantas foram cortadas no nível do substrato. As raízes foram separadas do substrato e lavadas com água destilada. Ambas as partes foram colocadas em sacos de papel individuais, os quais foram levados à estufa a $65{ }^{\circ} \mathrm{C}$, onde permaneceram até os tecidos vegetais atingirem peso constante, efetuando-se a determinação da massa seca da parte aérea e raízes.

O diâmetro do colo foi determinado com auxílio de paquímetro universal. Para a determinação da percentagem de colonização radicular, utilizou-se a técnica das intersecções de Giovanetti \& Mosse (1980), modificado por Brundrett et al. (1996). 
Os dados de altura da muda, diâmetro do colo, massa seca da parte aérea e raízes e percentual de colonização ectomicorrízica foram submetidos à análise de variância e ao teste de médias pelo teste de Tukey a $5 \%$ de probabilidade de erro pelo software SISVAR (Ferreira, 2000).

\section{Resultados e discussão}

Analisando-se os resultados referentes à altura e ao diâmetro do colo das mudas de eucalipto submetidas à aplicação do óleo essencial de Eucalyptus grandis (Tabela
1), observou-se que houve interação significativa entre a inoculação dos fungos ectomicorrízicos e a aplicação do óleo essencial. A adição do óleo essencial de eucalipto interferiu no crescimento das mudas, dependendo da sua concentração e do isolado ectomicorrízico utilizado. As mudas inoculadas com o fECM Pisolithus microcarpus (UFSC Pt 116) e submetidas à adição do óleo essencial de eucalipto na concentraçâo de $40 \mu \mathrm{L} \mathrm{L}^{-1}$, apresentaram altura significativamente superior em relação às dosagens 0 e $20 \mu \mathrm{L} \mathrm{L}^{-1}$. Já para o diâmetro do colo, não houve diferença significativa quando da utilização do óleo essencial nas concentrações de 30 e $40 \mu \mathrm{L} \mathrm{L}^{-1}$ (Tabela 1).

Tabela 1. Altura e diâmetro do colo de mudas de Eucalyptus grandis aos 90 dias após a micorrização e o início da aplicação de diferentes concentrações do óleo essencial de eucalipto.

\begin{tabular}{|c|c|c|c|c|c|}
\hline \multirow{2}{*}{ Tratamento } & \multicolumn{5}{|c|}{ Concentração } \\
\hline & $0 \mu \mathbf{L} \mathbf{L}^{-1}$ & $20 \mu L L^{-1}$ & $30 \mu \mathrm{L} \mathrm{L}^{-1}$ & $40 \mu L^{-1}$ & $50 \mu \mathbf{L} \mathbf{L}^{-1}$ \\
\hline \multicolumn{6}{|c|}{ Altura das mudas $(\mathrm{cm})$} \\
\hline Sem fungo & $18,02 \mathrm{bB}$ & $18,35 \mathrm{bB}$ & $19,70 \mathrm{bA}$ & $19,00 \mathrm{c} \mathrm{AB}$ & $18,81 \mathrm{c} \mathrm{AB}$ \\
\hline UFSC Pt 116 & $24,80 \mathrm{aB}$ & $24,88 \mathrm{aB}$ & 25,94 a $\mathrm{AB}$ & 27,80 a $\mathrm{A}$ & 26,80 a $\mathrm{AB}$ \\
\hline UFSC Pt 24 & $24,42 \mathrm{aB}$ & $26,17 \mathrm{aA}$ & 25,61 a A & $25,30 \mathrm{~b} \mathrm{AB}$ & $24,48 \mathrm{~b} \mathrm{AB}$ \\
\hline $\mathrm{CV}(\%)^{*}$ & 4,42 & 5,56 & 4,91 & 3,94 & 5,15 \\
\hline \multicolumn{6}{|c|}{ Diâmetro do colo (mm) } \\
\hline Sem fungo & $1,72 \mathrm{~b} \mathrm{~B}$ & 1,77 b B & $2,00 \mathrm{c} \mathrm{A}$ & $1,72 \mathrm{cB}$ & $1,79 \mathrm{cB}$ \\
\hline UFSC Pt 116 & 2,52 a B & 2,67 a B & 2,94 a A & $2,92 \mathrm{aA}$ & $2,70 \mathrm{aB}$ \\
\hline UFSC Pt 24 & 2,42 a $A B$ & 2,46 a $\mathrm{AB}$ & $2,62 \mathrm{~b} \mathrm{AB}$ & $2,67 \mathrm{bA}$ & $2,40 \mathrm{bB}$ \\
\hline $\mathrm{CV}(\%)^{*}$ & 6,26 & 7,82 & 3,40 & 2,87 & 6,74 \\
\hline
\end{tabular}

Médias seguidas pela mesma letra minúscula na coluna e maiúscula na linha não diferem entre si pelo teste de Tukey a $5 \%$ de probabilidade;

* Coeficiente de variação; Médias de oito repetições $(\mathrm{n}=8)$.

Para o fungo Pisolithus sp. (UFSC Pt 24), a aplicação do óleo essencial de eucalipto na concentração de 20 e $40 \mu \mathrm{L} \mathrm{L}^{-1}$ proporcionou aumentos significativos na altura das mudas e no diâmetro do colo, respectivamente, embora as concentrações de 20 e $30 \mu \mathrm{L} \mathrm{L}^{-1}$ não tenham apresentado diferença significativa para a altura das mudas (Tabela 1).

A altura e o diâmetro do colo demonstram o efeito de concentração do óleo essencial sobre os isolados ectomicorrízicos (Tabela 1). Com a utilização do óleo na concentração de $50 \mu \mathrm{L} \mathrm{L}^{-1}$, iniciou-se o decréscimo no crescimento das mudas, evidenciando o efeito antagonista do óleo essencial quando em concentrações elevadas (Batish et al., 2004).

Os resultados encontrados neste trabalho corroboram com os encontrados por Ludley et al. (2009), os quais descrevem que a resposta de fECM à presença de metabólitos secundários dos vegetais não está condicionada apenas à concentração dos compostos presentes, mas ao gênero, à espécie e até mesmo ao isolado micorrízico exposto a estes compostos.

Analisando-se os resultados referentes apenas à inoculação de fECM nas mudas de Eucalyptus grandis, evidencia-se que a inoculação resultou em plantas com maior desenvolvimento, visto que as ectomicorrizas, através de seu manto fúngico, podem absorver e armazenar glicogênio, proteínas e lipídios, além dos nutrientes inorgânicos, como N, P, K e Ca (Smith \& Read, 2008). Outro efeito observado corresponde à influência do óleo essencial aplicado nas mudas não micorrizadas, onde a concentração de $30 \mu \mathrm{L} \mathrm{L}^{-1}$ proporcionou plantas maiores e com caule mais desenvolvido (Tabela 1). Desta forma, a aplicação do óleo essencial nas mudas de Eucalyptus grandis pode ter ocasionado tanto modificações enzimáticas e/ou fisiológicas no vegetal, devido à ativação de elicitores, como pela inibição 
seletiva de microrganismos associados à rizosfera das mudas, os quais estariam associados a estresses bióticos de crescimento, ou a promoção do desenvolvimento de microrganismos capazes de produzir hormônios vegetais, como citocininas, giberelinas e ácido indol-3-acético e vitaminas, como riboflavina, niacina e vitamina B12, que contribuem para o crescimento vegetal (Leinhos \& Vacek, 1994), sendo chamados de microrganismos helpers (Duponnois \& Garbaye, 1990).

O crescimento vegetal ocorrido nos tratamentos onde houve a adição do óleo essencial de eucalipto também pode estar associado à presença de compostos fenólicos e terpenos, os quais atuam no estímulo ao crescimento da planta devido, não somente à presença de hormônios, mas também de componentes de membrana, além de atuarem na síntese de glicoproteínas e como transportadores de açúcares na parede celular (Taiz \& Zeiger, 2004).

Observou-se que os benefícios oriundos da inoculação, tanto para os parâmetros de altura e diâmetro do colo (Tabela 1) como para massa seca da parte aérea, foram maiores nos tratamentos onde ocorreu a inoculação dos isolados fúngicos aliada à aplicação do óleo essencial de eucalipto, quando comparados ao tratamento controle, não inoculado (Tabela 2).

Tabela 2. Massa seca da parte aérea e raízes das mudas de Eucalyptus grandis aos 90 dias após a micorrização e o início da aplicação de diferentes concentrações do óleo essencial de eucalipto.

\begin{tabular}{|c|c|c|c|c|c|}
\hline \multirow{2}{*}{ Tratamento } & \multicolumn{5}{|c|}{ Concentração } \\
\hline & $0 \mu \mathbf{L} \mathbf{L}^{-1}$ & $20 \mu L L^{-1}$ & $30 \mu \mathrm{L} \mathrm{L}^{-1}$ & $40 \mu \mathrm{L} \mathrm{L} \mathrm{L}^{-1}$ & $50 \mu \mathbf{L} \mathbf{L}^{-1}$ \\
\hline \multicolumn{6}{|c|}{ Massa seca da parte aérea (mg) } \\
\hline Sem fungo & $343 \mathrm{bC}$ & $591 \mathrm{cA}$ & $584 \mathrm{bA}$ & $595 \mathrm{cA}$ & $523 \mathrm{cB}$ \\
\hline UFSC Pt 116 & $824 \mathrm{aC}$ & $850 \mathrm{bC}$ & $894 \mathrm{aB}$ & $956 \mathrm{aA}$ & $843 \mathrm{aC}$ \\
\hline UFSC Pt 24 & $856 \mathrm{aB}$ & $918 \mathrm{aA}$ & $869 \mathrm{aB}$ & $797 \mathrm{bB}$ & $780 \mathrm{bC}$ \\
\hline $\mathrm{CV}(\%)^{*}$ & 2,96 & 4,48 & 3,89 & 3,98 & 2,66 \\
\hline \multicolumn{6}{|c|}{ Massa seca das raízes (mg) } \\
\hline Sem fungo & $0,873 \mathrm{aB}$ & $1,019 \mathrm{bA}$ & $1,009 \mathrm{bA}$ & $1,017 \mathrm{bA}$ & $0,868 \mathrm{bB}$ \\
\hline UFSC Pt 116 & $1,315 \mathrm{aB}$ & $1,193 \mathrm{aB}$ & $1,303 \mathrm{aB}$ & $1,344 \mathrm{aA}$ & $1,162 \mathrm{aB}$ \\
\hline UFSC Pt 24 & $1,271 \mathrm{aAB}$ & $1,129 \mathrm{bB}$ & $1,154 \mathrm{bB}$ & $1,292 \mathrm{aA}$ & $1,280 \mathrm{aAB}$ \\
\hline $\mathrm{CV}(\%)^{*}$ & 9,15 & 10,59 & 7,12 & 7,33 & 7,27 \\
\hline
\end{tabular}

Médias seguidas pela mesma letra minúscula na coluna e maiúscula na linha não diferem entre si pelo teste de Tukey a $5 \%$ de probabilidade;

* Coeficiente de variação; Média de oito repetições $(n=8)$.

Avaliando-se o efeito da inoculação micorrízica, verificou-se que a utilização de ambos os isolados proporcionou aumentos significativos nos valores de massa seca da parte aérea das mudas (Tabela 2). Esses dados corroboram com os encontrados por Souza et al. (2004) e Silva et al. (2007), que verificaram maior crescimento da parte aérea em plantas de Eucalyptus spp. inoculadas com fECM.

Para as mudas não micorrizadas, a adição do óleo essencial nas concentrações de 20 a $40 \mu \mathrm{L} \mathrm{L}^{-1}$ resultou em plantas mais desenvolvidas, de acordo com o maior acúmulo de tecidos (Tabela 2). Já nas mudas inoculadas com isolados ectomicorrízicos, a adição do óleo essencial nas concentrações de 20 e $40 \mu \mathrm{L} \mathrm{L}^{-1}$ resultou em plantas mais desenvolvidas, quando inoculadas com os isolados UFSC Pt 24 e UFSC Pt 116, respectivamente
(Tabela 2). Estes resultados podem ter ocorrido devido a interações entre o óleo essencial e a planta, resultando em incrementos no crescimento vegetal. Mafia et al. (2005) e Bonaldo et al. (2007) descrevem que a aplicação de óleos essenciais sobre as plantas resulta na ativação de mecanismos de defesa latentes ou reguladores do crescimento, como fitoalexinas e citocininas.

O valor de massa seca da planta é considerado a variável mais útil para medir o efeito de tratamentos sobre o crescimento das plantas (Bonnassis, 2007). A adição do óleo essencial, em determinadas concentrações, mostrou-se eficiente no crescimento vegetal de mudas de eucalipto em condições de viveiro. Também se observou que as plantas referentes aos tratamentos onde houve inoculação com fungos e adição do óleo essencial de eucalipto apresentaram maior desenvolvimento 
radicular. Quando inoculadas com os isolados UFSC Pt 116 e UFSC Pt 24, as mudas apresentaram maior massa seca das raízes quando submetidas à aplicação do óleo essencial de eucalipto na concentração de 40 $\mu \mathrm{L} \mathrm{L}-1$ (Tabela 2).

Segundo Narloch (2002) a colonização micorrízica promove alterações fisiológicas e trocas especializadas entre os simbiontes, estabelecendo um novo equilíbrio microbiano na região de influência da raiz colonizada. Desta forma, plantas cujo sistema radicular esteja habitado por microrganismos benéficos, como no caso de rizobactérias e fungos micorrízicos, apresentam crescimento superior ao crescimento de plantas cultivadas em substratos estéreis (Banchio et al., 2009).

Observou-se que a aplicação do óleo essencial de eucalipto na concentração de $40 \mu \mathrm{L} \mathrm{L}^{-1}$ resultou em aumentos significativos na porcentagem de colonização ectomicorrízica de plantas inoculadas com o isolado UFSC Pt 116, e que a adição do óleo essencial nas concentrações de 20 e $30 \mu \mathrm{L} \mathrm{L}^{-1}$ resultou em aumentos significativos na percentagem de colonização ectomicorrízica de plantas inoculadas com o isolado UFSC Pt 24 (Figura 1).

Mucciarelli et al. (2003) també,observaram aumento na colonização in vitro e in vivo de fungos endofíticos não micorrízicos, quando da utilização do óleo essencial de Mentha piperita L.

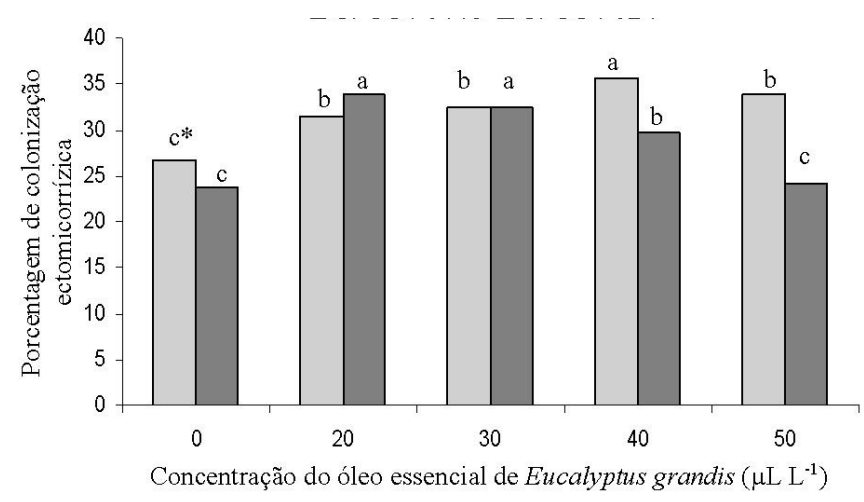

Figura 1. Porcentagem de colonização ectomicorrízica das raízes de Eucalyptus grandis aos 90 dias após a micorrização e o início da aplicação de diferentes concentrações do óleo essencial de eucalipto. *Médias seguidas pela mesma letra, em cada isolado, não diferem entre si pelo teste de Tukey a $5 \%$ de probabilidade. UFSC Pt 116 CV (\%) 4,14. UFSC Pt $24 \mathrm{CV}(\%) 4,81$.
Observou-se também que o efeito inibitório do óleo essencial sobre a colonização ectomicorrízica foi mais evidente no isolado UFSC Pt 24, quando houve aplicação em concentrações acima de $40 \mu \mathrm{L} \mathrm{L}^{-1}$ (Figura 1).

Baptista et al. (1999), em estudos quanto à produção de compostos fenólicos durante a simbiose ectomicorrízica, descrevem que compostos fenólicos vegetais induzem genes catabólicos em diversos microrganismos, assim como genes atuantes na formação e manutenção das simbioses com plantas. Estes compostos agem direta ou indiretamente na sinalização entre planta hospedeira e microrganismo, interferindo no metabolismo vegetal.

Para o estabelecimento da simbiose micorrízica é necessária a presença de metabólitos secundários da planta hospedeira. Após formada a associação, o fungo continua desencadeando na planta mecanismos de defesa, os quais permanecem estimulando a produção de compostos fenólicos responsáveis pela regulação desta simbiose (Bâ et al., 2010). Larose et al. (2002) observaram alterações prolongadas na concentração de flavonóides metabolizados por plantas colonizadas por fungos micorrízicos. Segundo Luo et al. (2009) apenas fungos capazes de formar associação ectomicorrízica possuem capacidade de suportar o estresse osmótico decorrente da simbiose fungo-planta, devido à presença dos metabólitos secundários na micorrizosfera.

A transdução de sinal observada no processo de simbiose é semelhante à observada no processo de patogênese de plantas. Mas, no caso da simbiose (a exemplo dos fECM) a resposta de defesa da planta é temporária e significativamente inferior, cessando após o estabelecimento da associação (Garcia-Garrido \& Ocampo, 2002; Hahlbrock et al., 2003; Hause \& Fester, 2005). Desta forma, acredita-se que o efeito de estímulo ao crescimento das plantas inoculadas e que receberam o óleo essencial esteja relacionado, entre outros fatores, ao estímulo à colonização micorrízica, visto que, apesar da adição destes compostos ao meio ter ocorrido de forma artificial, estes foram extraídos de planta formadora de associação ectomicorrízica, podendo conter assim, sinais bioquímicos envolvidos na formação e manutenção da simbiose micorrízica.

Copetta et al. (2006) avaliando a relação existente na interface fungo micorrízico e óleo essencial em plantas de Ocimum basilicum L., observaram que a alteração nos componentes do óleo essencial influenciou a porcentagem de colonização das raízes. Os autores atribuíram este efeito à concentração de determinados 
componentes, os quais atuam na interface fungo-planta.

Considerando-se os benefícios que a aplicação do óleo essencial proporcionou às mudas de eucalipto micorrizadas, resultando em plantas mais desenvolvidas, fica evidente o efeito benéfico da aplicação do óleo essencial, visto que este estimulou a colonização ectomicorrízica (Figura 1), resultando em plantas de maior porte e com maior massa seca (Tabelas 1 e 2).

$\mathrm{O}$ aumento na colonização ectomicorrízica resultou em incrementos no crescimento vegetal de forma diferenciada, dependendo do isolado ectomicorrízico utilizado. Quando as mudas foram inoculadas com o fungo Pisolithus microcarpus (UFSC Pt 116), verificouse que quanto maior a colonização ectomicorrízica, mais homogêneo o crescimento da planta tanto em altura como em massa seca. Já, quando da utilização do fungo Pisolithus sp. (UFSC Pt 24), a resposta de crescimento das plantas em relação ao aumento da colonização ectomicorrízica foi mais heterogêneo, principalmente para a massa seca da parte aérea das plantas.

De forma geral, os efeitos da utilização dos óleos essenciais, tanto inibitórios como sinérgicos, podem ser atribuídos aos compostos fenólicos e terpenos, com ênfase aos monoterpenos e sesquiterpenos presentes na composição dos metabólitos secundários de plantas bioativas (Hahlbrock et al., 2003; Batish et al., 2004; Ryabushkina, 2005; Zhi-lin et al., 2007).

Quanto à possibilidade de utilização comercial de metabólitos secundários de plantas bioativas na agricultura, Zhi-Lin et al. (2007) descrevem que, em curto prazo, a engenharia metabólica manipulará sinais bioquímicos de origem vegetal, a fim de serem utilizados na formação de associações micorrízicas em larga escala.

\section{Conclusões}

O óleo essencial de eucalipto nas concentrações de 20 a $40 \mu \mathrm{L} \mathrm{L}^{-1}$ proporciona aumento no crescimento da parte aérea e nas raízes das mudas de eucalipto. A colonização ectomicorrízica em mudas de eucalipto é estimulada na presença do óleo essencial de eucalipto até a concentração de $40 \mu \mathrm{L} \mathrm{L}^{-1}$ e concentrações acima desse valor reduzem o crescimento das mudas de eucalipto.

\section{Referências}

AKIYAMA, K.; MATSUZAKI, K.; HAYASHI, H. Plant sesquiterpenes induce hyphal branching in arbuscular mycorrhizal fungi. Nature, London, v. 435, p. 824-827, 2005.

ALVES, L.; OLIVEIRA, V. L. de; SILVA FILHO, G. N. Utilization of rocks and ectomycorrhizal fungi to promote growth of eucalypt. Brazilian Journal of Microbiology, São Paulo, v. 41, n. 3, p. 676-684, 2010.

BÂ, A. M.; DIÉDHIOU, A. G.; PRIN, Y.; GALIANA, A.; DUPONNOIS, R. Management of ectomycorrhizal symbionts associated to useful exotic tree species to improve reforestation performances in tropical Africa. Annals of Forest Science, Champenoux, v. 67, n. 3, p. 298-307, 2010.

BANCHIO, E.; XIE, X.; ZHANG, H.; PARE, P. W. Soil bacteria elevate essential oil accumulation and emissions in sweet basil.

Journal of Agriculture and Food Chemistry, Davis, v. 57, n. 2, p. 653-657, 2009.

BAPTISTA, M. J; GLORIA, B. A.; PASCHOLATI, S. F.; KRUGNER, T. L. Produção de compostos fenólicos durante a infecção ectomicorrízica por dois isolados de Pisolithus tinctorius em Eucalyptus urophylla in vitro. Revista Brasileira de Botânica, São Paulo, v. 22, n. 2, p. 309-315, 1999.

BATISH, D. R.; SETIA, N.; SINGH, H. P. Phytotoxicity of lemonscented eucalyptus oil and its potential use as a bioherbicide. Crop Protection, Washington, DC, v. 23, n. 12, p. 1209-1214, 2004.

BÉCARD, G.; KOSUTA, S.; TAMASLOUKHT, M.; SÉJALONDELMAS, N.; ROUX, C. Partner communication in the arbuscular mycorrhizal interaction. Canadian Journal of Botany, Guelph, v. 82, n. 8, p. 1186-1197, 2004.

BONALDO, S. M.; SCHWAN-ESTRADA, K. R. F.; STANGARLIN, J. R.; CRUZ, M. E. S.; FIORI-TUTIDA, A. C. G. Contribuição ao estudo das atividades antifúngica e elicitora de fitoalexinas em sorgo e soja por eucalipto (Eucalyptus citriodora). Summa Phytopathologica, Botucatu, v. 33, n. 4, p. 383-387, 2007.

BONNASSIS, P. A. P. Caracterização de isolados fúngicos ectomicorrízicos na promoção do crescimento e na colonização radicular de Eucalyptus dunnii Maiden. 2007. 69 f. Dissertação (Mestrado em Biotecnologia) - Universidade Federal de Santa Catarina, Florianópolis.

BRUNDRETT, M.; BOUGHER, N.; DELL, B.; GROVE, T.; MALAJCZUK, N. Working with mycorrhizas in forestry and agriculture. Canberra: ACIAR, 1996. 374 p.

BRUNDRETT, M. C. Mycorrhizal associations and other means of nutrition of vascular plants: understanding global diversity of host plants by resolving conflicting information and developing reliable means of diagnosis. Plant and Soil, Dordrecht, v. 320, n. 1-2, p. 37-77, 2009.

CHÁVEZ, D. M.; PEREIRA, G. C.; MACHUCA, Á. H. Efecto de tipos de inóculos de tres especies fúngicas en la micorrización controlada de plántulas de Pinus radiata. Bosque, Valdivia, v. 30, n. 1, p. 4-9, 2009. 
COPETTA, A.; LINGUA, G.; BERTA, G. Effects of three AM fungi on growth, distribution of glandular hairs, and essential oil production in Ocimum basilium L. var. Genovese. Mycorrhiza, Dijon Cedex, v. 16, n. 7, p. 485-494, 2006.

DOMENECH, J.; RAMOS SOLANO, B.; PROBANZA, A.; LUCAS GARCÍA, J. A.; COLÓN, J. J.; GUTIERREZ MAÑERO, F. J. Bacillus spp. and Pisolithus tinctorius effects on Quercus ilex ssp. ballota: a study on tree growth, rhizosphere community structure and mycorrhizal infection. Forest Ecology and Management, Victoria, v. 194, n. 1-3, p. 293-303, 2004.

DUÑABEITIA, M. K.; HORMILLA, S.; GARCÍA-PLAZAOLA, J. I.; TXARTERINA, K.; ARTECHE, U.; BECERRIL, J. M. Differential responses of three fungal species to environmental factors and their role in the mycorrhization of Pinus radiata D. Don. Mycorrhiza, Oregon, v. 14, n. 1, p.11-18, 2004.

DUPONNOIS, R.; GARBAYE, J. Some mechanisms involved in growth stimulation of ectomycorrhizal fungi by bacteria. Canadian Journal of Botany, Guelph, v. 68, p. 2148-2152, 1990.

FABROWSKI, F. J.; MUÑIZ, G. I. B.; NAKASHIMA, T.; NISGOSKI, S.; KLOCK, U. Investigação da presença de óleo essencial em Eucalyptus smithii R.T. Baker por meio da anatomia de seu lenho e casca. Ciência Florestal, Santa Maria, RS, v. 13, n. 1, p. 95-106, 2003.

FERREIRA, D. F. Sistemas de análise estatística para dados balanceados. Lavras, MG: UFLA/DEX/SISVAR, 2000. 145 p.

GARCÍA-GARRIDO, J. M.; OCAMPO, J. A. Regulation of the plant defence response in arbuscular mycorrhizal symbiosis.

Journal of Experimental Botany, Lancaster, v. 53, n. 373, p. 1377-1386, 2002.

GIACHINI, A. J.; SOUZA, L. A. B.; OLIVEIRA, V. L. Species richness and seasonal abundance of ectomycorrhizal fungi in plantations of Eucalyptus dunnii and Pinus taeda in southern Brazil. Mycorrhiza, Oregon, v. 14, n. 6, p. 375-381, 2004.

GIOVANETTI, M. G.; MOSSE, B. An evaluation of techniques for measuring vesicular-arbuscular mycorrhizal infection in roots. New Phytologist, Lancaster, v. 84, n. 3, p. 489-500, Mar. 1980.

HAHLBROCK, K.; BEDNAREK, P.; CIOLKOWSKI, I.; HAMBERGER, B.; HEISE, A.; LIEDGENS, H.; LOGEMANN, E.; NURNBERGER, T.; SCHMELZER, E.; SOMSSICH, I. E.; TAN, J. Non-self recognition, transcriptional reprogramming, and secondary metabolite accumulation during plant/pathogen interactions. Proceedings of the National Academy of Sciences of the United States of America, Washington, DC, v. 100, n. 2, p. 14569-14576, 2003.

HAUSE, B.; FESTER, T. Molecular and cell biology of arbuscular mycorrhizal symbiosis. Planta, Bonn, v. 221, n. 2, p. 184-196, 2005.

HOAGLAND, D. R.; ARNON, D. I. The water culture method for growing plants without soil. Berkeley, CA: University of California, 1950. (California Agricultural Experiment Station. Circular, 347).

HOBBIE, E. A. Carbon allocation to ectomycorrhizal fungi correlates with belowground allocation in culture studies. Ecology, Davis, v. 87, n. 3, p. 563-569, 2006.
LEINHOS, V.; VACEK, O. Biosynthesis of auxins by phosphatesolubilizing rhizobacteria from wheat (Triticum aestivum) and rye (Secale cereale). Microbiology Research, Beijing, v. 149, p. 31-35, 1994.

LUDLEY, K. E.; ROBINSON, C. H.; JICKELLS, S. Differential response of ectomycorrhizal and saprotrophic fungal mycelium from coniferous forest soils to selected monoterpenes. Soil Biology and Biochemistry, Brisbane, v. 40, n. 3, p. 669-678, 2008.

LUDLEY, K. E.; ROBINSON, C. H.; JICKELLS, S. Potential for monoterpenes to affect ectomycorrhizal and saprotrophic fungal activity in coniferous forest is revealed by novel experimental system. Soil Biology and Biochemistry, Brisbane, v. 41, n. 1, p. 117-124, 2009.

LUO, Z. B.; JANZ, D.; JIANG, X. N.; GOBEL, C.;

WILDHAGEN, H. Upgrading root physiology for stress tolerance by ectomycorrhizas: insights from metabolite and transcriptional profiling into reprogramming for stress anticipation. Plant Phisiology, Urbana, v. 151, n. 4, p. 1902-1917, 2009.

MAFIA, R. G.; ALFENAS, A. C.; FERREIRA, E. M.; ZARPELON, T. G.; SIQUEIRA, L. de. Crescimento de mudas e produtividade de minijardins clonais de eucalipto tratados com rizobactérias selecionadas. Revista Árvore, Viçosa, MG, v. 29, n. 6, p. 843-851, 2005.

MARX, D. H. The influence of ectotrophic mycorrhizal fungi on the resistance of pine roots to pathogenic fungi and soil bacteria. I. Antagonism of mycorrhizal fungi to root pathogenic fungi and soil bacteria. Phytopathology, Saint Paul, v. 59, p. 153-163, 1969.

MEIJER, A. A. R. de. Mycological work in the Brazilian State of Paraná. Nova Hedwigia, Stuttgart, v. 72, n. 1-2, p. 105-159, 2001.

MELLO, A. H.; ANTONIOLLI, Z. I.; KAMINSKI, J.; SOUZA, E. L.; OLIVEIRA, V. L. Fungos arbusculares e ectomicorrízicos em áreas de eucalipto e de campo nativo em solo arenoso. Ciência Florestal, Santa Maria, RS, v. 16, n. 3, p. 293-301, 2006.

MELLO, A. H.; ANTONIOLLI, Z. I.; KAMINSKI, J.; SOUZA, E. L.; OLIVEIRA, V. L. Estabelecimento a campo de mudas de Eucalyptus grandis micorrizadas com Pisolithus microparcus (UFSC Pt 116) em solo arenoso. Ciência Florestal, Santa Maria, RS, v. 19, n. 2, p. 149-155, 2009.

MUCCIARELLI, M.; SCANNERINI, S.; BERTEA, C. In vitro and in vivo peppermint (Mentha piperita) growth promotion by nonmycorrhizal fungal colonization. New Phytologist, Lancaster, v. 158, n. 3, p. 579-591, June 2003.

NARLOCH, C. Interação microrganismos solubilizadores de fosfatos: fungos ectomicorrízicos e o crescimento de Pinus taeda L. 2002. 171 f. Dissertação (Mestrado em Biotecnologia) Universidade Federal de Santa Catarina, Florianópolis.

PERA, J.; PARLADÉ, J. Inoculación controlada con hongos ectomicorrícicos en la producción de planta destinada a repoblaciones forestales: estado actual en España. Investigación Agraria: sistemas y recursos forestales, Madrid, v. 14, n. 3, p. 419-433, 2005. 
PEREIRA, O. L.; COSTA, M. D.; BORGES, A. C.; ARAÚJO, E. F.; KASUYA, M. C. M. Compatibility and ectomycorrhiza formation among Pisolithus isolates and Eucalyptus spp. Revista Brasileira de Ciência do Solo, Viçosa, MG, v. 29, n. 3, p. 337344, 2005.

PROBANZA, A.; MATEOS, J. L.; LUCAS GARCIA, J. A.; RAMOS, B.; FELIPE, M. R. de.; GUTIERREZ MAÑERO, F. J. Effects of inoculation with PGPR Bacillus and Pisolithus tinctorius on Pinus pinea L. growth, bacterial rhizosphere colonization, and mycorrhizal infection. Microbial Ecology, Rockville, v. 41, n. 2, p.140-148, 2001.

RINCÓN, A.; RUIZ-DÍEZ, B.; GARCÍA-FRAILE, S.; GARCÍA, J. A. L.; FERNÁNDEZ-PASCUAL, M.; PUEYO, J. J.; FELIPE,

M. R. de. Colonization of Pinus halepensis roots by Pseudomonas fluorescens and interaction with the ectomycorrhizal fungus Suillus granulatus. FEMS Microbiology Ecology, Aberdeen, v. 51, n. 3, p. 303-311, 2005.

ROSSI, M. J.; FURIGO JUNIOR, A.; OLIVEIRA, V. L. Inoculant production of ectomycorrhizal fungi by solid and submerged fermentations. Food Technology and Biotechnology, Zagreb, v. 45, n. 3, p. 277-286, 2007.

RYABUSHKINA, N. A. Synergism of metabolite action in plant responses to stress. Russian Journal of Plant Physiology, Moscow, v. 52, n. 4, p. 547-552, 2005.

SERAFINI, L. A.; CASSEL, E. Produção de óleos essenciais: uma alternativa para a agroindústria nacional. In: SERAFINI, L. A.; BARROS, N. M.; AZEVEDO, J. L. Biotecnologia na agricultura e na agroindústria. Guaíba: Agroindústria, 2001. p. 333-377.

SILVA, M. A.; COSTA, M. D.; ROCHA, R. B.; BORGES, A. C. Formação de ectomicorrizas por monocários e dicários de Pisolithus sp. e interações nutricionais em Eucalyptus grandis. Revista Brasileira de Ciência do Solo, Viçosa, MG, v. 31, n. 5, p. 917-929, set./out. 2007.

SMITH, S. E.; READ, D. J. Mycorrhizal symbiosis. 3rd. ed. San Diego: Academic Press, 2008. 787 p.
SOUZA, L. A. B. de; SILVA FILHO, G. N.; OLIVEIRA, V. L. de. Eficiência de fungos ectomicorrízicos na absorção de fósforo e na promoção do crescimento de eucalipto. Pesquisa Agropecuária Brasileira, Brasília, DF, v. 39, n. 4, p. 349-355, 2004.

SOUZA, L. A. B.; SILVA FILHO, G. N.; OLIVEIRA, V. L. de. Novos isolados de fungos ectomicorrízicos e o crescimento de eucalipto. Pesquisa Agropecuária Brasileira, Brasília, DF, v. 43, n. 2, p. 235-241, 2008.

TAIZ, L.; ZEIGER, E. Plant Physiology. 4th. ed. Massachusetts: Sinauer Associates 2006. 764 p.

TARKKA, M.; NEHLS, V.; HAMPP, R. Physiology of ectomicorrhiza (ECM). Progress in botany, Verlag, v. 66, p. 247276, 2005.

TREVISAN, R.; HASELEIN, C. R.; SANTINI, E. J.; SCHNEIDER, P. R. Efeito da intensidade de desbaste nas características dendrométricas e tecnológicas da madeira de Eucalyptus grandis. Ciência Florestal, Santa Maria, RS, v. 17, n. 4, p. 377-387, 2007.

VITTI, A. M. S.; BRITO, J. O. Óleo essencial de Eucalipto. São Paulo: Escola Superior de Agricultura "Luiz de Queiroz", 2003. 26 f. (Documentos, 17).

WENKE, K.; KAI, M.; PIECHULLA, B. Belowground volatiles facilitate interactions between plant roots and soil organisms. Planta, Bonn, v. 231, n. 3, p. 499-506, 2010.

YUWA-AMORNPITAK, T. Molecular characterization of ectomycorrhizal fungi associated on eucalyptus root sustem in Mashasarakham Province. Journal of Science and Technology Mabasarakham University, v. 28, n. 1, p. 101-109, 2009.

ZHI-LIN, Y.; CHUAN-CHAO, D.; LIAN-QING, C. Regulation and accumulation of secondary metabolites in plant-fungus symbiotic system. African Journal of Biotechnology, Bowie, v. 6, n. 11, p. 1266-1271, 2007. 
